\title{
Effects of goats' or cows' milks on nutritive utilization of calcium and phosphorus in rats with intestinal resection
}

\author{
Margarita S. Campos*, Inmaculada López-Aliaga, María J. M. Alférez, Teresa Nestares and \\ Mercedes Barrionuevo \\ Department of Physiology, Institute of Nutrition and Food Technology, University of Granada, E-18071 Granada, \\ Spain
}

(Received 15 July 2002 - Revised 16 December 2002 - Accepted 11 February 2003)

\begin{abstract}
We analysed the effects of goats' milk (GM) on the nutritive utilization of $\mathrm{Ca}$ and $\mathrm{P}$ in rats with resection of $50 \%$ distal small intestine in comparison with cows' milk (CM) and a standard non-milk diet. The three test diets contained $200 \mathrm{~g}$ protein and $100 \mathrm{~g}$ fat $/ \mathrm{kg}$. The apparent digestibility coefficient (ADC) of $\mathrm{Ca}$ and $\mathrm{P}$ were considerably higher in the two groups of rats given the GM diet than those given the other two diets. $\mathrm{Ca}$ and $\mathrm{P}$ retention did not decrease by effect of intestinal resection with GM diet. In both groups of animals, serum Ca and $\mathrm{P}$ levels and ionic $\mathrm{Ca}$ were higher in the case of the GM diet than the other two diets, whereas the parathyroid hormone levels were lower. Ca content in femur, sternum and longissimus dorsi muscle was higher in rats given the GM diet. P content in femur and sternum was higher among the two groups of rats given a milk-based diet (GM or CM), especially with GM diet. The GM diet has beneficial effects on nutritive utilization of $\mathrm{Ca}$ and $\mathrm{P}$ in control rats and those with resection of the distal small intestine.
\end{abstract}

Calcium: Phosphorus: Goats' milk: Cows' milk: Intestinal resection

In an earlier study we showed that the distal resection of the small intestine provokes adverse effects on the homeostasis of $\mathrm{Ca}$ and $\mathrm{P}$ in rats (Barrionuevo et al. 1989; Campos et al. 1989). The modification of lipids in the diet using a mixture of equal parts of medium-chain triacylglycerol, olive oil and sunflower oil raises $\mathrm{Ca}$ and $\mathrm{P}$ absorption, preferentially by active transport (López Aliaga et al. 1994; Alférez et al. 1996), both in transected (control) animals and in those with resection of $50 \%$ distal small intestine.

One of the main reasons why milk is considered a food of exceptional quality is due to the minerals it provides, and especially $\mathrm{Ca}$ and $\mathrm{P}$, in optimum proportions for absorption (Ca:P 1.0-1.5). While both milk and milk products are an important source of $\mathrm{Ca}$, goats' milk (GM) is especially so. As remarked by Moreno (1995), the consumption of a suitable quantity of $\mathrm{Ca}$, in proportion to that of $\mathrm{P}$, would be difficult without the inclusion in the diet of a considerable amount of milk or milk-based products. GM is rich in medium-chain triacylglycerol compared with human milk and cows' milk (CM) (Haenlein, 1996), a factor that is important in the nutritive utilization of Ca and P (López Aliaga et al. 1994; Alférez et al. 1996).

Taking these considerations into account, we studied the effects of GM on the digestive and metabolic utilization of $\mathrm{Ca}$ and $\mathrm{P}$ and the mineral content in various organs of transected (control) and resected rats (50\% distal small intestine). A comparative study was made with a $\mathrm{CM}$ diet and a non-milk diet recommended by the American Institute of Nutrition (1977).

\section{Materials and methods}

Animals

The study carried out on sixty-nine animals (white male rats, Ratus novergicus, Wistar albino breed), with an initial body weight of 177 (SE 3) g, obtained from the University of Granada Laboratory Animal Service. After surgery, both the transected (control) and resected animals were housed in individual, ventilated, thermoregulated $\left(22 \pm 2^{\circ} \mathrm{C}\right)$ cages with a $12 \mathrm{~h}$ light-dark period. Food and mineralfree water were available ad libitum to all rats.

\section{Assurance of compliance}

All experiments and surgical procedures using rats conformed to the guidelines and legal requirements established in the UK for the proper care and use of laboratory animals.

Diets

The diets, mineral and vitamin supplements were prepared according to the recommendations of the American 
Institute of Nutrition (1977), except that the level of fat in the diets was 100 rather than $50 \mathrm{~g} / \mathrm{kg}$ (Table 1). The standard non-milk diet was prepared using olive oil as the source of fat $(100 \mathrm{~g} / \mathrm{kg})$ and casein as the protein source $(200 \mathrm{~g} / \mathrm{kg})$. The milk-based diets were created with lyophilized CM or GM respectively. These were analysed to determine the fat $(\mathrm{CM} 352.3$, GM $436.3 \mathrm{~g} / \mathrm{kg})$, protein (CM 239.2, GM 252.7 g/kg) and lactose (CM 355.5, GM $311.0 \mathrm{~g} / \mathrm{kg}$ ) contents and mineral compositions $(\mathrm{mg} / \mathrm{kg}$ lyophilized milk): CM Ca 10315, P 7313, Mg 763, Fe 6.1, $\mathrm{Cu} 1 \cdot 1, \mathrm{Zn}$ 37.2; GM Ca 12152, P 8433, Mg 825, Fe 11.3, $\mathrm{Cu} 4 \cdot 2, \mathrm{Zn} 41 \cdot 5$. The necessary quantities of lyophilized $\mathrm{CM}$ or GM were taken to obtain a diet with a fat content of $100 \mathrm{~g} / \mathrm{kg}$. To obtain the protein content of $200 \mathrm{~g} / \mathrm{kg}$ (as recommended by the American Institute of Nutrition (1977)) the diet was supplemented with casein (125.3 g casein $/ \mathrm{kg} \mathrm{CM}$ diet and $140.5 \mathrm{~g}$ casein $/ \mathrm{kg} \mathrm{GM}$ diet), as the protein provided by the lyophilate used for the milkbased diets was insufficient.

Table 1. Composition of the experimental diets

\begin{tabular}{|c|c|}
\hline Component & $\mathrm{g} / \mathrm{kg}$ diet (dry weight) \\
\hline \multicolumn{2}{|l|}{ Diet S (standard non-milk) } \\
\hline Protein (casein) & 209 \\
\hline DL-Methionine & 3 \\
\hline Fat (olive oil)* & 112 \\
\hline Fibre (micronized cellulose) & 50 \\
\hline Mineral supplement† & 36 \\
\hline Vitamin supplement $†$ & 10 \\
\hline Choline chloride & 2 \\
\hline Wheat starch & $15 \overline{6}$ \\
\hline Sucrose & 450 \\
\hline Energy (kJ/kg diet) & 17890 \\
\hline \multicolumn{2}{|l|}{ Diet $C M$} \\
\hline Protein (casein+CM protein) & 190 \\
\hline DL-Methionine & 3 \\
\hline Fat $(\mathrm{CM}) \ddagger$ & 98 \\
\hline Fibre (micronized cellulose) & 40 \\
\hline Mineral specific supplement§ & 35 \\
\hline Vitamin specific supplement§ & 10 \\
\hline Choline chloride & 2 \\
\hline Wheat starch & $15 \overline{2}$ \\
\hline Sucrose & 487 \\
\hline Energy (kJ/kg diet) & 17598 \\
\hline \multicolumn{2}{|l|}{ Diet GM } \\
\hline Protein (casein+GM protein) & 194 \\
\hline DL-Methionine & 3 \\
\hline Fat $(\mathrm{GM}) \|$ & 92 \\
\hline Fibre (micronized cellulose) & 46 \\
\hline Mineral specific supplement§ & 36 \\
\hline Vitamin specific supplement§ & 10 \\
\hline Choline chloride & 2 \\
\hline Wheat starch & $15 \overline{3}$ \\
\hline Sucrose & 485 \\
\hline Energy (kJ/kg diet) & 17422 \\
\hline
\end{tabular}

CM, cows' milk; GM, goats' milk.

${ }^{*}$ Contains a $0.0 \mathrm{~g}$ medium-chain triacylglycerol $/ \mathrm{kg}$

† Mineral and vitamin supplements were prepared according to the recommendations of the American Institute of Nutrition (1977).

¥ Contains $20.6 \mathrm{~g}$ medium-chain triacylglycerol $/ \mathrm{kg}$.

$\$$ Mineral and vitamin specific supplements were formulated taking into account the mineral content of the lyophilized milks supplied in order to meet the mineral-content recommendations of the American Institute of Nutrition (1977).

|| Contains $33.2 \mathrm{~g}$ medium-chain triacylglycerol $/ \mathrm{kg}$.
The mineral supplements were prepared according to American Institute of Nutrition (1977) recommendations for the standard non-milk diet and to our own specifications for the milk-based diets. These specific supplements were formulated taking into account the mineral content of the lyophilized milks supplied to the rats in order to meet the mineral content recommendations of the American Institute of Nutrition (1977; $5200 \mathrm{mg} \mathrm{Ca}$ and $4000 \mathrm{mg} \mathrm{P} / \mathrm{kg}$ diet).

The lactose content of the milk diets was subtracted from the total carbohydrate content of the standard diet and wheat starch and sucrose was added corresponding to the difference (Table 1).

\section{Resection and transection procedures}

The method described by Hartiti et al. (1994) was used to carry out the resection of $50 \%$ of the distal small intestine in rats. Animals in which the intestine was transected were treated identically except that the small intestine was only divided and reanastomosed at the mid-small intestine, without exclusion of any part of intestine. These transected rats were the control groups, because they maintained the whole intestine and all the blood supply.

\section{Experimental design}

Six experimental groups were formed: (1) group T-S, transected (control) rats, standard non-milk diet (n 11); (2) group $\mathrm{R}-\mathrm{S}$, resected rats, standard non-milk diet (n 13); (3) group T-CM, transected (control) rats, CM diet (n 10); (4) group R-CM, resected rats, CM diet (n 11); (5) group T-GM, transected (control) rats, GM diet ( $n$ 14); (6) group R-GM, resected rats, GM diet ( $n$ 10).

All animals were fed up to the time of surgery, and were given access to water containing $50 \mathrm{~g}$ glucose/l for $24 \mathrm{~h}$ after surgery. Thereafter, a period of $30 \mathrm{~d}$ was allowed for adaptation to the diet, during which feed and mineralfree water were available ad libitum to all animals. Beginning $30 \mathrm{~d}$ after surgery, food intake (the amount of food consumed per $\mathrm{d}$ by each rat determined by weighing the amounts of diet given, refused and spilled) was measured and urine and faeces were collected each $\mathrm{d}$ for a period of $7 \mathrm{~d}$ (Thomas \& Mitchell, 1923). The urine for the $7 \mathrm{~d}$ of the experimental period was collected on $\mathrm{HCl}(5 \mathrm{ml} / \mathrm{l})$, filtered (Whatman filter paper no. 42; Whatman, Maidstone, Kent, UK) and diluted. The faeces for the $7 \mathrm{~d}$ experimental period were dried, weighed and homogenized. Body weight was recorded at the beginning and end of the experimental period. Throughout the experimental period all rats had access to mineral-free water. At the end of this period, all animals were fasted for $24 \mathrm{~h}$ and killed after intraperitoneal anaesthesia with sodium pentobarbital (50 mg/kg body weight) and totally bled by cannulation of the abdominal aorta. The entire volume of blood was centrifuged at $3500 \mathrm{rpm}$ for $12 \mathrm{~min}$ to separate the serum, which was frozen at $-30^{\circ} \mathrm{C}$ until biochemical analysis. The femur, sternum, longissimus dorsi muscle, liver, spleen, kidneys, heart, brain and testes were dissected, frozen at $-20^{\circ} \mathrm{C}$, freeze-dried, homogenized and kept dry until analysed. 


\section{Biological indices}

The apparent digestibility coefficient (ADC) and balance were calculated according to the following formulas:

where

$$
\operatorname{ADC}(\%)=(\text { absorbed } / \text { intake }) \times 100,
$$
and

nutrient absorption $=$ intake - faecal excretion,

balance $=$ intake $-($ faecal + urinary excretion $)$.

\section{Analytical techniques}

Dry matter. Water content in the diet, faeces, femur, sternum, longissimus dorsi muscle, liver, spleen, kidney, heart, brain and testis was determined by drying the material at $105 \pm 2^{\circ} \mathrm{C}$ until the weight remained constant (about $48 \mathrm{~h}$ ).

Ash. A sample of the resulting sample (diet, faeces and liver; $1-2 \mathrm{~g}$ ) or the entire sample (femur, sternum, longissimus dorsi muscle, spleen, kidney, heart, brain, testis) was oven-ashed at $450^{\circ} \mathrm{C}$. The residue obtained was weighed and then diluted in $5 \mathrm{M}-\mathrm{HCl}$ to which mineral-free water was added to a predetermined volume for subsequent analysis.

Mineral determination. The concentration of $\mathrm{Ca}$ in the diet, faeces and the different organs were determined by atomic absorption spectrophotometry (Perkin-Elmer 1100 B; Perkin-Elmer, Shelton, CT, USA) and compared with a series of standard values. The concentration of $\mathrm{P}$ in the diet, faeces, serum and the different organs was analysed by visible spectrophotometry (Perkin-Elmer UV/vis spectrometer lambda 16) using the Fiske-Subbarow technique (Fiske \& Subbarow, 1925).

Serum calcium concentrations. The serum concentrations of $\mathrm{Ca}$ were determined by colorimetry, using the method of Sarkar \& Chauvan (1967).

Serum ionized calcium. Ionic $\mathrm{Ca}$ was measured with an autoanalyser using a NOVA 7 selective electrode (Nova Biomedical, Waltham, MA, USA).

Parathyroid hormone. Parathyroid hormone was determined with a radioimmunoassay for the C-terminal/half molecule of the hormone (Nichols Institute, San Juan Capistrano, CA, USA) measured with a Packard counter (Packard, Meriden, CT, USA).

\section{Quality control}

Given the importance of accurate determination of the various variables studied, the measurements of these were subjected to a quality control procedure. This consisted of analysing a skimmed milk powder (certified reference material CRM 063R; Community Bureau of Reference, Brussels, Belgium), which yielded a mean $\mathrm{Ca}$ value 13.89 (SEM 0.10) and a P value 10.99 (SEM 0.12) $\mathrm{mg} / \mathrm{g}$ ( $n$ 5 determinations) (certified values: Ca 13.49 (SEM $0 \cdot 10$ ) and P $11 \cdot 10$ (SEM 0.13) $\mathrm{mg} / \mathrm{g}$ ).

\section{Statistical analyses}

We calculated the mean values with their standard errors for each variable studied. The data were analysed statistically by two-way ANOVA using a model with two main effects (animal group and type of diet) (SPSS, version 9.0.1, 2001; SPSS Inc., Chicago, IL, USA). Values of $P<0.05$ were considered significant.

\section{Results \\ Apparent digestibility coefficient and balance of calcium and phosphorus}

The ADC for $\mathrm{Ca}$ and $\mathrm{P}$ were significantly reduced in the resected animals for the three diets studied $(P<0.05)$. The ADC of $\mathrm{Ca}$ and $\mathrm{P}$ were considerably higher in the two groups of rats given the GM diet than those given the other two diets, non-milk standard and CM (standard non-milk diet $P<0.01$ for $\mathrm{Ca}$ and $P<0.001$ for $\mathrm{P}$ in transected and resected rats; $\mathrm{CM} P<0.001$ for $\mathrm{Ca}$ and $\mathrm{P}$ in transected and resected rats respectively). The ADC for $\mathrm{Ca}$ and $\mathrm{P}$ in both animals groups fed the standard nonmilk diet and $\mathrm{CM}$ diet did not differ significantly (ADC of $\mathrm{Ca}$ and $\mathrm{P}$ GM $>$ standard non-milk=CM) (Tables 2 and 3). The $\mathrm{Ca}$ and $\mathrm{P}$ balance did not vary between the transected (control) and the resected animals fed with $\mathrm{GM}$ diet and were reduced in resected rats fed with $\mathrm{CM}$ diet or with standard non-milk diet $(P<0.05)$ for $\mathrm{Ca}$ and $\mathrm{P}$. In transected (control) and resected animals, the $\mathrm{Ca}$ and $\mathrm{P}$ retention were greater when the GM diet was consumed than when the standard non-milk diet was given (transected rats $P<0.05$ for $\mathrm{Ca}$ and $P<0.01$ for $\mathrm{P}$, resected rats $P<0.01$ for $\mathrm{Ca}$ and $P<0.001$ for $\mathrm{P}$ ) (Tables 2 and 3 ). In transected rats, the retention of $\mathrm{Ca}$ was higher with the $\mathrm{CM}$ diet than the standard non-milk diet $(P<0 \cdot 05)$. To compare both types of milk, it is evident that only the $P$ retention was higher in resected rats fed with GM diet in relation to resected rats fed with $\mathrm{CM}$ diet $(P<0 \cdot 01)$ (Tables 2 and 3 ).

\section{Serum concentrations of calcium (total and ionic), phosphorus and parathyroid hormone}

The concentrations of total $\mathrm{Ca}$ and $\mathrm{P}$ in serum were not affected by the intestinal resection, for any of the three diets studied (Table 4). In the case of $\mathrm{Ca}$, among the transected (control) and resected rats, the serum concentrations were higher when a milk diet (GM or $\mathrm{CM}$ ) was consumed than when the standard non-milk diet was given $(P<0.001)$; in particular, the serum $\mathrm{Ca}$ was higher when the animals consumed the GM diet in comparison with the $\mathrm{CM}$ diet $(P<0.001)$ (Table 4$)$. However, serum ionized $\mathrm{Ca}$ was affected by intestinal resection for the three diets tested (standard diet $P<0.05, \mathrm{CM}$ diet $P<0 \cdot 01$, GM diet $P<0 \cdot 001)$, whereas the effect of different type of diets on ionic $\mathrm{Ca}$ shows a similar pattern to total serum $\mathrm{Ca}$, thus the serum ionized $\mathrm{Ca}$ was higher when a milk diet, specially GM, diet was consumed $(P<0.001)$ (Table 4$)$.

In transected (control) and resected rats, the concentrations of $\mathrm{P}$ in serum were higher when the GM diet was consumed than either the CM diet $(P<0.001)$ or the standard non-milk diet $(P<0 \cdot 001)$. Standard non-milk and $\mathrm{CM}$ diets resulted in similar concentrations of $\mathrm{P}$ in serum in both animals groups (Table 4 ). 
Table 2. Digestive and metabolic utilization of calcium in transected and resected rats fed on standard non-milk or milk diets (cows' (CM) or goats' (GM))§

(Mean values with their standard errors)

\begin{tabular}{|c|c|c|c|c|c|c|c|c|c|c|c|c|c|}
\hline \multirow[b]{2}{*}{ Group } & \multirow[b]{2}{*}{$n$} & \multicolumn{2}{|c|}{$\begin{array}{c}\text { Ca intake } \\
\text { (mg/rat per d) }\end{array}$} & \multicolumn{2}{|c|}{$\begin{array}{l}\text { Faecal Ca }(\mathrm{mg} / \mathrm{rat} \\
\text { per d) }\end{array}$} & \multicolumn{2}{|c|}{$\begin{array}{l}\text { Absorbed Ca } \\
\text { (mg/rat per d) }\end{array}$} & \multicolumn{2}{|c|}{ ADC (\%) } & \multicolumn{2}{|c|}{$\begin{array}{l}\text { Urinary Ca } \\
(\mathrm{mg} / \text { rat per d) }\end{array}$} & \multicolumn{2}{|c|}{$\begin{array}{l}\text { Ca balance } \\
\text { (mg/rat per d) }\end{array}$} \\
\hline & & Mean & SE & Mean & SE & Mean & $\mathrm{SE}$ & Mean & SE & Mean & SE & Mean & SE \\
\hline T-S & 11 & $87 \cdot 1$ & $2 \cdot 8$ & $59 \cdot 2$ & 2.5 & $28 \cdot 0$ & $1 \cdot 6$ & $32 \cdot 2$ & 1.5 & 1.9 & 0.1 & $26 \cdot 1$ & 1.6 \\
\hline R-S & 13 & $89 \cdot 1$ & $3 \cdot 1$ & 65.5 & 2.9 & $23 \cdot 6$ & 1.4 & $26 \cdot 5^{\star}$ & 1.7 & $1 \cdot 7$ & 0.2 & $21.9^{*}$ & 1.4 \\
\hline T-CM & 10 & $105 \cdot 4 \dagger \dagger \dagger$ & 2.5 & 73.0††† & 3.1 & 32.4 & $2 \cdot 2$ & $30 \cdot 8$ & $2 \cdot 0$ & $1.9 \dagger \dagger \dagger$ & 0.1 & $30.5 \dagger$ & 1.2 \\
\hline $\mathrm{R}-\mathrm{CM}$ & 11 & $112 \cdot 8 \dagger \dagger \dagger$ & 3.0 & $83 \cdot 6^{\star}+\dagger \dagger$ & $2 \cdot 2$ & $29 \cdot 3+\dagger$ & 1.5 & $25 \cdot 9^{*}$ & 1.0 & $3 \cdot 5^{\star}+\dagger$ & 0.4 & $25 \cdot 7^{\star}$ & 1.4 \\
\hline T-GM & 14 & $83 \cdot 6 \ddagger \ddagger \ddagger$ & 1.7 & 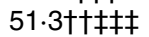 & 0.9 & 32.3 & 1.5 & 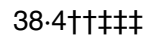 & 1.3 & 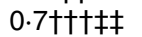 & 0.1 & $31.6 \dagger$ & 1.5 \\
\hline R-GM & 10 & 86.8†拉 & 3.2 & 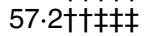 & $2 \cdot 8$ & $29 \cdot 6+\dagger$ & 1.5 & 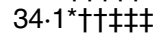 & $1 \cdot 6$ & $0.8 \neq \ddagger$ & 0.3 & $28.7 \dagger \dagger$ & $1 \cdot 3$ \\
\hline
\end{tabular}

ADC, apparent digestibility coefficient; T-S, transected rats fed on the standard non-milk diet; R-S, resected rats fed on the standard non-milk diet; T-CM, transected rats fed on the CM diet; R-CM, resected rats fed on the CM diet; T-GM, transected rats fed on the GM diet; R-GM, resected rats fed on the GM diet. Mean values were significantly different from those of the transected groups: ${ }^{*} P<0.05$.

Mean values were significantly different from those corresponding standard non-milk group: $\dagger P<0 \cdot 05$. $\dagger \dagger P<0 \cdot 01$. $\dagger \dagger \dagger P<0 \cdot 001$.

Mean values were significantly different from those of the coresponding CM group: $\ddagger \ddagger P<0.01$. $\ddagger \ddagger \ddagger P<0.001$.

$\S$ For details of diets and procedures see Table 1 and pp. 61-62.

Table 3. Digestive and metabolic utilization of phosphorus in transected and resected rats fed on standard non-milk or milk diets (cows' (CM) or goats' (GM))§

(Mean values with their standard errors)

\begin{tabular}{|c|c|c|c|c|c|c|c|c|c|c|c|c|c|}
\hline \multirow[b]{2}{*}{ Group } & \multirow[b]{2}{*}{$n$} & \multicolumn{2}{|c|}{$\begin{array}{c}\text { P intake } \\
(\mathrm{mg} / \text { rat per d) }\end{array}$} & \multicolumn{2}{|c|}{$\begin{array}{l}\text { Faecal P (mg/rat } \\
\text { per d) }\end{array}$} & \multicolumn{2}{|c|}{$\begin{array}{l}\text { Absorbed P } \\
\text { (mg/rat per d) }\end{array}$} & \multicolumn{2}{|c|}{ ADC (\%) } & \multicolumn{2}{|c|}{$\begin{array}{c}\text { Urinary P } \\
\text { (mg/rat per d) }\end{array}$} & \multicolumn{2}{|c|}{$\begin{array}{c}\text { P balance }(\mathrm{mg} / \mathrm{rat} \\
\text { per } \mathrm{d})\end{array}$} \\
\hline & & Mean & $\overline{S E}$ & Mean & $\overline{\mathrm{SE}}$ & Mean & $\overline{\mathrm{SE}}$ & Mean & $\overline{\mathrm{SE}}$ & Mean & $\overline{\mathrm{SE}}$ & Mean & $\overline{\mathrm{SE}}$ \\
\hline T-S & 11 & 71.7 & 2.3 & 31.9 & 1.7 & 39.8 & 1.5 & 55.6 & 1.4 & $25 \cdot 0$ & 1.4 & $14 \cdot 8$ & 1.7 \\
\hline R-S & 13 & 73.3 & 2.5 & 35.9 & 1.3 & 36.7 & 1.7 & $50 \cdot 0^{*}$ & 1.4 & $27 \cdot 2$ & 1.3 & $9 \cdot 5^{\star}$ & 1.2 \\
\hline $\mathrm{T}-\mathrm{CM}$ & 10 & $81 \cdot 7 \dagger \dagger \dagger$ & $2 \cdot 0$ & $36.4 \dagger$ & 1.5 & $45 \cdot 3+\dagger$ & 1.6 & 55.5 & 1.5 & $26 \cdot 1$ & 1.4 & $19 \cdot 2$ & $2 \cdot 2$ \\
\hline $\mathrm{R}-\mathrm{CM}$ & 11 & $85.6+t \dagger$ & 1.4 & $42 \cdot 4^{\star *}+\dagger$ & 1.4 & $43 \cdot 3+\dagger$ & 1.7 & $50 \cdot 6^{*}$ & 1.6 & 30.4 & 1.8 & $12 \cdot 9^{\star}$ & 1.6 \\
\hline T-GM & 14 & $68.0 \pm \pm \ddagger$ & 1.4 & 22.9†十t执 & 0.9 & $45 \cdot 1+t$ & 1.0 & 66.5十七十执 & $1 \cdot 1$ & 23.1 & 1.1 & $22.0+t$ & 1.2 \\
\hline R-GM & 10 & $70.5 \ddagger \ddagger \ddagger$ & 1.6 & 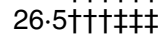 & 1.9 & $44.0+\dagger$ & 1.4 & 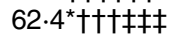 & 1.4 & $24 \cdot 0 \neq \ddagger$ & 1.3 & 20.0†††㧊 & 1.8 \\
\hline
\end{tabular}

ADC, apparent digestibility coefficient; T-S, transected rats fed on the standard non-milk diet; R-S, resected rats fed on the standard non-milk diet; T-CM, transected rats fed on the CM diet; R-CM, resected rats fed on the CM diet; T-GM, transected rats fed on the GM diet; R-GM, resected rats fed on the GM diet.

Mean values were significantly different from those of the transected groups: ${ }^{\star} P<0.05,{ }^{*} P<0.01$.

Mean values were significantly different from those corresponding standard non-milk group: $\dagger P<0 \cdot 05$. $\dagger \dagger P<0 \cdot 01$. $\dagger \dagger \dagger P<0 \cdot 001$.

Mean values were significantly different from those of the coresponding CM group: $\ddagger \ddagger P<0.01 . ~ \ddagger \ddagger \ddagger P<0.001$.

$\S$ For details of diets and procedures see Table 1 and pp. 61-62.

Table 4. Serum concentrations of calcium (total and ionic), phosphorus and parathyroid hormone in transected and resected rats fed on standard non-milk or milk diets (cows' (CM) or goats' (GM))§

(Mean values with their standard errors)

\begin{tabular}{|c|c|c|c|c|c|c|c|c|c|c|c|c|}
\hline & \multicolumn{2}{|c|}{$\mathrm{T}-\mathrm{S}(n 11)$} & \multicolumn{2}{|c|}{$\mathrm{R}-\mathrm{S}(n$ 13) } & \multicolumn{2}{|c|}{ T-CM (n 10) } & \multicolumn{2}{|c|}{$\mathrm{R}-\mathrm{CM}(n 11)$} & \multicolumn{2}{|c|}{ T-GM (n 14) } & \multicolumn{2}{|l|}{ R-GM (n 10) } \\
\hline & Mean & SE & Mean & SE & Mean & SE & Mean & SE & Mean & SE & Mean & SE \\
\hline Serum Ca (mg/l) & $100 \cdot 1$ & 0.7 & $98 \cdot 2$ & 0.7 & 107.3††† & 0.6 & $106 \cdot 1 \dagger † \dagger$ & 0.8 & 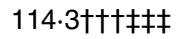 & 0.8 & 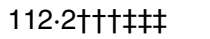 & 0.9 \\
\hline Serum ionized $\mathrm{Ca}(\mathrm{mg} / \mathrm{l})$ & $58 \cdot 1$ & 0.3 & $57 \cdot 3^{*}$ & 0.4 & 61.4††† & 0.4 & $59 \cdot 3^{\star *}+\dagger †$ & 0.4 & 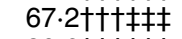 & 0.5 & 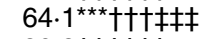 & 0.4 \\
\hline Serum P (mg/l) & 73.4 & 1.9 & $73 \cdot 0$ & $1 \cdot 3$ & $74 \cdot 3$ & $1 \cdot 1$ & $73 \cdot 2$ & $1 \cdot 6$ & 80.6†††キ†† & 0.9 & 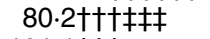 & 1.4 \\
\hline Parathyroid hormone (ng/l) & $121 \cdot 3$ & $3 \cdot 4$ & $124 \cdot 4$ & $4 \cdot 3$ & $109 \cdot 2 \dagger$ & $3 \cdot 3$ & $110 \cdot 9 \dagger$ & $4 \cdot 8$ & 98.2††† & $2 \cdot 7$ & 101.1††† & 2.4 \\
\hline
\end{tabular}

$\mathrm{T}-\mathrm{S}$, transected rats fed on the standard non-milk diet; R-S, resected rats fed on the standard non-milk diet; T-CM, transected rats fed on the CM diet; R-CM, resected rats fed on the CM diet; T-GM, transected rats fed on the GM diet; R-GM, resected rats fed on the GM diet.

Mean values were significantly different from those of the transected groups: ${ }^{\star} P<0.05$, ${ }^{\star *} P<0.01$, ${ }^{\star * \star} P<0.001$.

Mean values were significantly different from those corresponding standard non-milk group: $\dagger P<0 \cdot 05$. $\dagger \dagger P<0 \cdot 01$. $\dagger \dagger \dagger P<0 \cdot 001$.

Mean values were significantly different from those of the coresponding $\mathrm{CM}$ group: $\ddagger P<0.05$. $\ddagger \ddagger \ddagger P<0.001$.

$\S$ For details of diets and procedures see Table 1 and pp. 61-62.

The serum concentrations of parathyroid hormone were similar in transected and resected rats with the three types of diet studied. In relation to the type of diet, the diets based on milk and especially the GM diet, showed the lowest serum concentrations of parathyroid hormone in transected rats (GM $P<0.01, \mathrm{CM} P<0.05)$ and resected rats (GM $P<0.001$, CM $P<0.05$ ) with respect to the standard non-milk diet. To compare both types of milk, the GM caused lower parathyroid hormone concentrations with respect to the $\mathrm{CM}$ in transected animals $(P<0 \cdot 05)$ (Table 4$)$. 


\section{Mineral content in different organs}

In general, the deposit of $\mathrm{Ca}$ and $\mathrm{P}$ in the femur, sternum and in the longissimus dorsi muscle was very little affected at $37 \mathrm{~d}$ after the intestinal resection for the three types of diet studied, except in resected rats fed with $\mathrm{CM}$ diet for which the $\mathrm{Ca}$ content in femur was lower $(P<0.05)$ (Tables 5 and 6). In the case of $\mathrm{Ca}$, in transected (control) and resected rats, no differences were observed between the animals given the non-milk standard and the CM diets, except in femur that in transected animals the $\mathrm{Ca}$ content was higher with the $\mathrm{CM}$ diet than standard nonmilk diet $(P<0.001)$; the mineral deposit was greater, always, in the case of the GM diet $(P<0 \cdot 001)$ (Table 5). In relation to $\mathrm{P}$, and in general, the deposit in femur and sternum was greater in both animal groups given the milk-based diets, especially with GM diet (for significance levels, see Table 6). In the muscle, there was a greater quantity of $\mathrm{P}$ for both the transected (control) and the resected rats when the GM diet was consumed $(P<0.001)$, followed by the standard non-milk diet, while the lowest amount corresponded to the CM diet $(P<0 \cdot 01)$ for transected and resected rats (Table 6).

With respect to the other organs studied (liver, spleen, kidney, heart, brain and testis), the $\mathrm{Ca}$ content/g dry weight is in the order of $\mu \mathrm{g}$, well below the quantity found in the femur, the sternum and the muscle. In general, these levels were little affected by the type of diet consumed (Table 5).

In the case of $\mathrm{P}$, there was a notably higher content in the other organs studied (liver, spleen, kidney, heart, brain and testis) of the transected (control) and resected animals given the GM diet with respect to those consuming the $\mathrm{CM}$ diet (almost 2-fold, $P<0.001$ ) and the standard diet (except for heart and testis in transected rats, $P<0.001$ ) (Table 6).

Table 5. Calcium concentration in several organs ( $\mathrm{mg}$ or $\mu \mathrm{g} / \mathrm{g}$ dry weight) in transected and resected rats fed on standard non-milk or milk diets (cows' (CM) or goats' (GM))§

(Mean values with their standard errors)

\begin{tabular}{|c|c|c|c|c|c|c|c|c|c|c|c|c|}
\hline & \multicolumn{2}{|c|}{$\mathrm{T}-\mathrm{S}(n 11)$} & \multicolumn{2}{|c|}{$\mathrm{R}-\mathrm{S}(n 13)$} & \multicolumn{2}{|c|}{$\mathrm{T}-\mathrm{CM}(n 10)$} & \multicolumn{2}{|c|}{$\mathrm{R}-\mathrm{CM}(n 11)$} & \multicolumn{2}{|c|}{ T-GM (n 14) } & \multicolumn{2}{|c|}{ R-GM (n 10) } \\
\hline & Mean & SE & Mean & SE & Mean & SE & Mean & SE & Mean & SE & Mean & SE \\
\hline Femur (mg) & $233 \cdot 8$ & 0.8 & $227 \cdot 7$ & 4.5 & 241.8††† & $1 \cdot 0$ & $235 \cdot 3^{*}$ & $2 \cdot 7$ & 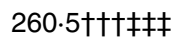 & $1 \cdot 6$ & 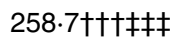 & $5 \cdot 0$ \\
\hline Sternum (mg) & $133 \cdot 3$ & 2.9 & $128 \cdot 6$ & 1.5 & $140 \cdot 5$ & $3 \cdot 1$ & $134 \cdot 3$ & $3 \cdot 0$ & 157.8†††††† & $2 \cdot 7$ & 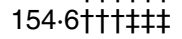 & $4 \cdot 3$ \\
\hline Longissimus dorsi (mg) & $5 \cdot 8$ & $0 \cdot 2$ & 5.5 & 0.3 & $5 \cdot 8$ & 0.3 & $5 \cdot 8$ & 0.3 & $7 \cdot 1 \dagger \ddagger \ddagger$ & 0.3 & 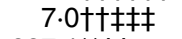 & 0.2 \\
\hline Liver $(\mu \mathrm{g})$ & 258.9 & $21 \cdot 2$ & $217 \cdot 8$ & $22 \cdot 6$ & 274.2 & $19 \cdot 8$ & $171 \cdot 1^{\star \star \star}$ & $8 \cdot 3$ & 301.0 & $15 \cdot 4$ & $237 \cdot 1^{\star \star} \ddagger \ddagger$ & 14.4 \\
\hline Spleen $(\mu \mathrm{g})$ & $148 \cdot 3$ & $9 \cdot 1$ & $142 \cdot 0$ & $7 \cdot 2$ & $128 \cdot 5 \dagger$ & 4.5 & $117 \cdot 8^{\star} \dagger † \dagger$ & 2.9 & 108.9†††‡ & 2.4 & $123 \cdot 7^{\star \star} \dagger$ & 3.0 \\
\hline Heart $(\mu g)$ & $88 \cdot 4$ & 2.5 & $83 \cdot 7$ & $2 \cdot 4$ & 106.2††† & $4 \cdot 0$ & 97.9†† & $3 \cdot 3$ & 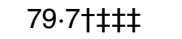 & $2 \cdot 7$ & $92.9^{*}$ & $5 \cdot 3$ \\
\hline Brain $(\mu \mathrm{g})$ & 592.9 & $48 \cdot 3$ & 491.6 & $37 \cdot 3$ & $430 \cdot 1 \dagger \dagger$ & $37 \cdot 3$ & 464.4 & $28 \cdot 6$ & 613.3击 & $31 \cdot 3$ & 666.2†††㧊 & 19.9 \\
\hline Testis $(\mu \mathrm{g})$ & $249 \cdot 6$ & $5 \cdot 2$ & $233 \cdot 4^{*}$ & $5 \cdot 6$ & 386.8††† & $12 \cdot 3$ & 375.8††† & $11 \cdot 7$ & 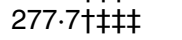 & $8 \cdot 1$ & $333 \cdot 2^{\star *}+† \dagger \ddagger$ & $16 \cdot 7$ \\
\hline
\end{tabular}

T-S, transected rats fed on the standard non-milk diet; R-S, resected rats fed on the standard non-milk diet; T-CM, transected rats fed on the CM diet; R-CM, resected rats fed on the CM diet; T-GM, transected rats fed on the GM diet; R-GM, resected rats fed on the GM diet.

Mean values were significantly different from those of the transected groups: ${ }^{\star} P<0.05,{ }^{\star \star} P<0.01,{ }^{\star \star \star} P<0.001$.

Mean values were significantly different from those corresponding standard non-milk group: $\dagger P<0.05, \dagger \dagger P<0.01, \dagger \dagger \dagger P<0.001$.

Mean values were significantly different from those of the coresponding CM group: $\ddagger P<0.05, \ddagger \ddagger P<0.01, \ddagger \ddagger \ddagger P<0.001$.

$\S$ For details of diets and procedures, see Table 1 and pp. 61-62.

Table 6. Phosphorus concentration in several organs (mg/g dry weight) in transected and resected rats fed on standard non-milk or milk diets (cows' (CM) or goats' (GM))§

(Mean values with their standard errors)

\begin{tabular}{|c|c|c|c|c|c|c|c|c|c|c|c|c|}
\hline & \multicolumn{2}{|c|}{$\mathrm{T}-\mathrm{S}(n 11)$} & \multicolumn{2}{|c|}{ R-S (n 13) } & \multicolumn{2}{|c|}{ T-CM (n 10) } & \multicolumn{2}{|c|}{$\mathrm{R}-\mathrm{CM}(n 11)$} & \multicolumn{2}{|c|}{ T-GM (n 14) } & \multicolumn{2}{|c|}{ R-GM (n 10) } \\
\hline & Mean & SE & Mean & SE & Mean & SE & Mean & SE & Mean & SE & Mean & SE \\
\hline Femur & $83 \cdot 1$ & 1.4 & $81 \cdot 1$ & $1 \cdot 2$ & $87 \cdot 3$ & 1.9 & $85.5 \dagger$ & 0.9 & $89.5 \dagger$ & $2 \cdot 4$ & $87.5 \dagger$ & $2 \cdot 8$ \\
\hline Sternum & $43 \cdot 1$ & 1.5 & $40 \cdot 1$ & $1 \cdot 2$ & $46.9 \dagger$ & 0.8 & 46.4††† & 0.9 & 49.3††† & 0.7 & 48.8††† & 1.0 \\
\hline Longissimus dorsi & $5 \cdot 1$ & 0.3 & 4.9 & 0.4 & 4.0†† & 0.2 & $3.7 \dagger \dagger$ & 0.2 & 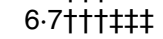 & 0.2 & 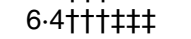 & 0.1 \\
\hline Liver & $5 \cdot 1$ & 0.2 & $5 \cdot 8^{\star}$ & 0.2 & $3 \cdot 2 \dagger \dagger \dagger$ & 0.1 & 3.6††† & 0.2 & 6.4†††††† & 0.1 & 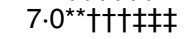 & $0 \cdot 2$ \\
\hline Spleen & $7 \cdot 5$ & 0.2 & $7 \cdot 1$ & 0.2 & $5 \cdot 2 \dagger \dagger \dagger$ & 0.3 & 4.8††† & $0 \cdot 1$ & 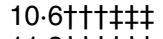 & 0.3 & 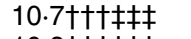 & 0.5 \\
\hline Heart & $6 \cdot 9$ & 0.1 & $5 \cdot 6^{\star \star \star}$ & 0.3 & 4.9††† & 0.2 & $3 \cdot 6^{* * *}$ †十 & 0.2 & $8 \cdot 2 \ddagger \ddagger \ddagger$ & 0.2 & 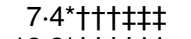 & 0.3 \\
\hline Brain & $8 \cdot 2$ & 0.1 & $8 \cdot 1$ & 0.1 & 5.8††† & 0.3 & $5 \cdot 7 \dagger † \dagger$ & 0.1 & 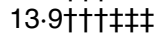 & 0.5 & 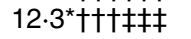 & 0.5 \\
\hline Testis & $7 \cdot 6$ & 0.3 & $5 \cdot 4^{\star \star \star}$ & 0.3 & 4.9††† & 0.1 & $4 \cdot 7$ & 0.1 & 8.1扞 & 0.2 & 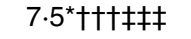 & 0.3 \\
\hline
\end{tabular}

T-S, transected rats fed on the standard non-milk diet; R-S, resected rats fed on the standard non-milk diet; T-CM, transected rats fed on the CM diet;

$\mathrm{R}-\mathrm{CM}$, resected rats fed on the CM diet; T-GM, transected rats fed on the GM diet; R-GM, resected rats fed on the GM diet.

Mean values were significantly different from those of the transected groups: ${ }^{\star} P<0.05$. ${ }^{\star \star} P<0.01,{ }^{\star \star \star} P<0.001$.

Mean values were significantly different from those of the corresponding standard non-milk group: $\dagger P<0.05, \dagger \dagger P<0.01, \dagger \dagger \dagger P<0.001$.

Mean values were significantly different from those of the coresponding CM group: $\ddagger \ddagger \ddagger P<0.001$.

$\S$ For details of diets and procedures, see Table 1 and pp. 61-62. 


\section{Discussion}

The ADC of $\mathrm{Ca}$ and $\mathrm{P}$ were reduced by the intestinal resection for the three diets tested. Thus, with the standard diet the $\mathrm{ADC}$ of $\mathrm{Ca}$ and $\mathrm{P}$ in resected rats is reduced by 17.7 and $10.1 \%$ respectively, while in previous studies carried out by our research group using rats with the same type of intestinal resection and diets with the same $\mathrm{Ca}$ and $\mathrm{P}$ content, this reduction was more pronounced $(60.8 \%$ for $\mathrm{Ca}$ and 46.1\% for P) (Barrionuevo et al. 1989; Campos et al. 1989). This minor effect might be explained by the fact that the quantities of protein $(200 \mathrm{~g} / \mathrm{kg})$ and fat $(100 \mathrm{~g} / \mathrm{kg})$ in the three diets tested were practically double those used in the earlier study $(120 \mathrm{~g}$ protein and $50 \mathrm{~g} \mathrm{fat} / \mathrm{kg}$ ) (Barrionuevo et al. 1989; Campos et al. 1989). In other studies with rats, it has been shown that an increase in the level of protein in the diet produces a corresponding increase in the absorption of $\mathrm{Ca}$ (Wapnir, 1989; Pallarés et al. 1993; Campos et al. 1996) and $\mathrm{P}$ (Pallarés et al. 1993; Campos et al. 1996). Moreover, Alférez et al. (1996) found that in rats with resection of the distal small intestine the proximal colon undergoes an adaptative response, there being an increase in the absorption capacity per unit of length and weight of intestinal mucosa. Thus, an increase in the level of protein in the diet, a factor that favours the bioavailability of $\mathrm{Ca}$, together with the greater absorption of this mineral due to the adaptative capacity of the large intestine could contribute to a greater ADC of $\mathrm{Ca}$. This present study confirms recent findings in human subjects and rats, which show that not only the distal intestine but also the hindgut may play an important role in Ca absorption (Younes et al. 1993, 1996, 2001; Greger, 1999).

With respect to the ADC of $\mathrm{P}$, casein, which is the principal protein in the three diets tested, contains about $7.2 \mathrm{~g}$ $\mathrm{P} / \mathrm{kg}$ casein, and when the proportion of casein in the diet rises from 120 to $200 \mathrm{~g} / \mathrm{kg}$, which represents an increase of $80 \mathrm{~g}$ casein $/ \mathrm{kg}$ diet, there is a corresponding increase in the levels of $\mathrm{P}$ (Reeves et al. 1993). This increase in the quantity of $\mathrm{P}$ in the intestinal lumen of resected rats could contribute to raise the absorption of $\mathrm{P}$ by difussion.

On the other hand, this is in accordance with a recent study by Alférez et al. (2001), where the absorption of fat in animals with intestinal resection rises when the lipid proportion in the diet is increased (from 50 to $100 \mathrm{~g} / \mathrm{kg}$ ), and approaches the levels found in intact animals.

The consumption of a GM diet, both by the transected (control) and the resected animals, increased the digestive utilization of $\mathrm{Ca}$ and $\mathrm{P}$ with respect to the other two diets (the non-milk standard and the CM diet). This might be due to the different protein and lipid quality of GM with respect to $\mathrm{CM}$ and the standard non-milk diet. GM contains a higher quantity of lysine $(3.4 \mathrm{~g} / \mathrm{l})$ than does CM $(2.8 \mathrm{~g} / \mathrm{l})$ (Souci et al. 1989). The beneficial effect of this basic amino acid seems to be related to the non-mediated transport of $\mathrm{Ca}$, and could be due to neutralization of organic acids by lysine, because these acids may bind to $\mathrm{Ca}$ and impair its absorption (Wapnir, 1990).

Moreover, GM has a higher medium-chain triacylglycerol content than CM (Haenlein, 1996) and increased micellar fatty acids in the ingesta increase local mucosal blood flow and perhaps increase passive uptake of $\mathrm{Ca}$ and $\mathrm{P}$.

On the other hand, the greater absorption of $\mathrm{Ca}$ and $\mathrm{P}$ in animals given the GM diet could be explained by the high vitamin D content of GM $(2 \cdot 5 \mu \mathrm{g} / \mathrm{l})$ with respect to $\mathrm{CM}$ (0.63 $\mu \mathrm{g} / \mathrm{l})$ (Souci et al. 1989); this vitamin favours the absorption of Ca (Campos et al. 1989; Alférez et al. 1996) and P (Barrionuevo et al. 1989; López Aliaga et al. 1994).

The results of the digestive utilization of $\mathrm{Ca}$ and $\mathrm{P}$ are complemented by the results for the balance (retention) of these two minerals.

The retentions of $\mathrm{Ca}$ and $\mathrm{P}$ were greater among the transected (control) than the resected animals, when the diet was non-milk standard or based on CM. When it was based on GM, it is noteworthy that there were no differences between the two groups of animals in this respect. This demonstrates the beneficial effects of the GM diet, which increases the retention of $\mathrm{Ca}$ and $\mathrm{P}$ in animals with intestinal resection. The retentions of $\mathrm{Ca}$ and $\mathrm{P}$ were higher amongst both groups of animals when the diets were based on milk, especially with GM, which could be due to the higher quantity of vitamin D in this type of milk (Souci et al. 1989). Vitamin D is known to have a beneficial effect on the retention of $\mathrm{Ca}$ (Campos et al. 1989).

The lower nutritive utilization of $\mathrm{Ca}$ and $\mathrm{P}$ in resected animals is reflected in only a small decline in the content of total $\mathrm{Ca}$ and $\mathrm{P}$ in serum. This effect is more evident when the ionic $\mathrm{Ca}$ is determined, and both the intestinal resection and the type of diet affected these concentrations. Thus, with the three diets studied the ionized Ca concentration was lower in rats with intestinal resection, and the milk-based diet (GM or CM), especially the GM milk diet, led to higher concentrations of both total and ionized $\mathrm{Ca}$ in serum. Blood $\mathrm{pH}$ was unchanged by the effect of resection, so the differences found in ionized $\mathrm{Ca}$ in serum could be justified because total plasma protein concentrations are affected by the intestinal resection and were relatively proportional to the changes in serum ionized $\mathrm{Ca}$ (López Aliaga et al. 2003). The parathyroid hormone concentrations showed a relationship between ionic $\mathrm{Ca}$ and this hormone and it is evident that when the ionic $\mathrm{Ca}$ concentrations were higher in rats fed with the milk-based diet, especially with GM diet, the parathyroid hormone serum concentrations were decreased.

At $37 \mathrm{~d}$ after the surgical intervention, the content or deposit of $\mathrm{Ca}$ in the preferential target organs for $\mathrm{Ca}$ (femur, sternum and the longissimus dorsi muscle) (Arnaud \& Sánchez, 1997) was virtually unchanged. However, the $\mathrm{Ca}$ content was higher in the muscle and bone (femur and sternum) among the rats given the GM diet than among those consuming the other two diets. Thus, GM could play an important role in preventing $\mathrm{Ca}$ deficiency. With reference to the $\mathrm{Ca}$ content in the other organs studied (liver, spleen, kidney, heart, brain, testis), these were within the normal ranges described in the literature for this species (Lisbona et al. 1999).

The GM diet had a positive effect on the deposit of $\mathrm{P}$ in the organs where the high consumption of ATP requires its presence (i.e. muscle, brain, kidney and spleen). 
The consumption of a natural food such as GM increases the nutritive utilization and deposit of $\mathrm{Ca}$ and $\mathrm{P}$ in the target organs for these minerals, both among the transected (control) and resected animals. In general, the GM reduces the negative effect of intestinal resection on $\mathrm{Ca}$ and $\mathrm{P}$ metabolism and approaches the values obtained to the transected animals (controls). For these reasons, extrapolating the results obtained in rats to man, the consumption of GM is advisable in situations of malabsorption syndrome and among the population in general.

\section{Acknowledgements}

We thank Ms Elisa Alcover for her efficient administrative support and Ms Rosa Jiménez for her competent technical assistance. This study was supported by the CICYT reword project no. ALI 96-1024-C02-02.

\section{References}

Alférez MJM, Barrionuevo M, López Aliaga I, Sanz-Sampelayo MR, Lisbona F \& Campos MS (2001) The digestive utilization of goat and cow milk fat in malabsorption syndrome. $J$ Dairy Res 68, 451-461.

Alférez MJM, López Aliaga I, Barrionuevo M, et al. (1996) Calcium absorption in rats with distal intestinal resection: Influence of type of dietary fat, cholecalciferol and nature of the adaptative response. Int J Vitam Nutr Res 66, 59-65.

American Institute of Nutrition (1977) Report of the American Institute of Nutrition Ad Hoc Committee on standards for nutritional studies. J Nutr 107, 1340-1348.

Arnaud CD \& Sánchez SD (1997) Calcium and phosphorus. In Present Knowledge in Nutrition, 7th ed., pp., 260-271 [EE Ziegler and LI Filer, editors]. Washington, DC: International Life Sciences Institute.

Barrionuevo M, Campos MS, López Aliaga I, Coves F \& Lisbona F (1989) Nutritive utilization of phosphorus in the rat: influence of intestinal resection, medium chain triglycerides and dietary vitamin $\mathrm{D}_{3}$. Int $J$ Vitam Nutr Res 59, 255-261.

Campos MS, López Aliaga I, Barrionuevo M, Lisbona F \& Coves F (1989) Nutritive utilization of calcium in rats: Effects of dietary fat components and vitamin $\mathrm{D}_{3}$ on intestinal resected rats. J Nutr Sci Vitaminol 35, 511-521.

Campos MS, Pallarés I, Moratalla A, et al. (1996) Bioavailability of $\mathrm{Fe}, \mathrm{Ca}, \mathrm{P}$ and $\mathrm{Mg}$ in $\mathrm{Fe}$-deficient rats treated with different sources of dietary iron. Nutr Res 16, 683-696.

Fiske CH \& Subbarow Y (1925) The colorimetric determination of phosphorus. J Biol Chem 66, 375-400.

Greger JL (1999) Nondigestible carbohydrates and mineral bioavailability. J Nutr 129, 1434S-1435S.

Haenlein GFW (1996) Nutritional value of dairy products of ewe and goat milk. Proceedings of the International Dairy Federation, Production and Utilization of Ewe and Goat Milk, pp. 159-178. Brussels: IDF National Committees.
Hartiti S, Lisbona F, LópezAliaga I, et al. (1994) Influence of dietary fat components and intestinal resection on iron, zinc and copper metabolism in rats. Int $J$ Vitam Nut Res 64, 330-336.

Lisbona F, Reyes-Andrada MD, López-Aliaga I, Barrionuevo M, Alférez MJM \& Campos MS (1999) The importance of the proportion of heme/nonheme iron in the diet to minimize the interference with calcium, phosphorus, and magnesium metabolism on recovery from nutritional ferropenic anemia. J Agri Food Chem 47, 2026-2032.

López Aliaga I, Alférez MJM, Lisbona F, et al. (1994) Influence of vitamin $\mathrm{D}_{3}$ and type of dietary fat on phosphorus absorption in rats with intestinal resection. Nut Res 14, 47-57.

López Aliaga, I, Alférez MJM, Barrionuevo M, Nestares T, Sanz Sampelago MR \& Campos MS (2003) Study on nutritive utilization of protein and magnesium in rats with resection of the distal small intestine. Beneficial effect of goat milk. $J$ Dairy Sci (In the Press).

Moreno R (1995) Dairy as an ideal source of calcium/phosphorus in the diet. ANS 2, 52-58.

Pallarés I, Lisbona F, López Aliaga I, Barrionuevo M, Alférez MJM \& Campos MS (1993) Effects of iron deficiency on the digestive utilization of iron, phosphorus, calcium and magnesium in rats. Br J Nutr 70, 609-620.

Reeves PG, Nielsen FH \& Fahey GC (1993) AIN-93 purified diets for laboratory rodents: final report of the American Institute of Nutrition and Ad Hoc Writing Committee on the reformulation of the AIN-76A rodent diet. J Nutr 123, 1939-1951.

Sarkar BCR \& Chauvan UPS (1967) A new method for determining micro quantities of calcium in biological materials. Anal Biochem 20, 155-166.

Souci SW, Fachmann W \& Kraut H (1989) In Food Composition and Nutrition Tables 1989/90, 4th ed., pp. 13 and 26. [B Garching, editor]. Munchen: Deutsche Forschungsanstalt für Lebensmittelchemie.

Thomas K \& Mitchell HH (1923) A method of determining the biological value of protein. J Biol Chem 58, 873-903.

Wapnir RA (1989) Protein digestion and absorption of mineral elements. In Mineral Absorption in the Monogastric Gastrointestinal Tract: Chemical, Nutritional and Physiological Aspects, pp. 151 [FR Dintzis and JA Laszlo, editors] Plenum Press New York.

Wapnir RA (1990) Calcium, magnesium and phosphorus absorption, nutritional status and effect of protein. In Protein Nutrition and Mineral Absorption, 8th ed pp. 77-97 [RA Wapnir, editor]. Boca Raton, FL: CRC Press, Inc.

Younes H, Coudray C, Bellanger J, Demigné C, Rayssiguier Y \& Rémésy C (2001) Effects of two fermentable carbohydrates (inulin and resistant starch) and their combination on calcium and magnesium balance in rats. Br J Nutr 86, 479-485.

Younes H, Demigne C \& Remesy C (1996) Acidic fermentation in the caecum increased absorption of calcium and magnesium in large intestine of the rat. Br J Nutr 75, 301-314.

Younes H, Levrat MA, Demigne C \& Remesy C (1993) Relationship between fermentations and calcium in the cecum of rats fed digestible or resistant starch. Ann Nutr Metabol 37, 311-319. 